\title{
Customer-Defined Quality and Quality-Based Product Portfolio: A Theoretical Framework on Quality
}

Xia Pan*

Lingnan College, Sun Yat-sen University, China

*Corresponding author: Xia Pan, Lingnan College, Sun Yat-sen University, China, Tel: 86-20-84110479; E-mail: panpapers@yahoo.com

Rec date: Dec 14, 2014, Acc date: Feb 25, 2015, Pub date: Feb 28, 2015

Copyright: (C) 2015 Pan X. This is an open-access article distributed under the terms of the Creative Commons Attribution License, which permits unrestricted use, distribution, and reproduction in any medium, provided the original author and source are credited.

\begin{abstract}
Most of the studies on quality to date are viewpoints from management, while the economics on quality were often ignored. In this paper, we emphasize that the principle of utility is the key to understand customer-defined quality. Based on the reviews and discussions on fundamental, economic perspectives on quality, especially the references of Taguchi's loss function and financial portfolio theory, we propose a preliminary theory and analytical framework on quality-based product portfolio.
\end{abstract}

Keywords: Customer-defined quality; Uncertainty; Higher moments; Risk; Quality-based product portfolio

\section{Introduction}

Originally quality means fitness for use. Quality inevitably becomes one of the properties of the product once the product is in exchange and in use. In modern definition, quality is inversely proportional to variability [1]. The aim of quality masters' such as Shewhart $[2,3]$ Deming [4-6], and Taguchi's [7-9] pioneer work on using statistical methods for quality control and improvement justifies this definition: looking for consistency. In fact, while modern production methods are mainly to enhance productivity, they often have the effect of reducing variability of the products. For example, in late nineteenth century Frederick Taylor divided work in mass production into tasks so that not only the products could be manufactured and assembled more easily and more efficiently, but also the standardized production and assembly methods reduced the variability of the product-a positive impact on quality.

Quality practitioners and researchers also view quality at business and management angles. A common viewpoint is that quality should be defined by customers; the goal of quality management is to satisfy customers' needs. Examples include the philosophy of Juran, one of the quality management masters, in his Juran trilogy--quality planning, quality control, and quality improvement. A company should 1)identify the customers and discover the customers' needs, 2)translate customers' needs to technical language of product (or service), develop the product and the processes to produce the product, 3)develop process control operations and deliver the product to customers [10]. Based on the identified customers' needs, firms should continuously improve their business and manufacturing operations to respond customers' requirements more precisely, then control the improved precision and deliver the improved products to their customers.

Well-founded economic theory supports the principles of customerdefined quality. However, in mainstream quality literature viewing quality from economic angles were not sufficiently addressed in popular. Especially, controversies appear around whether some quality management initiatives are really as successful as their advocators claimed, and whether these initiatives are losing their focus. More specifically, is quality itself or the bottom line the goal of quality management? When people talk about business excellence, how much weight on the bottom line is implied with the measurement? As we know, different initiatives emphasize differently on cost issue. Six Sigma focus more on bottom line than TQM does, while some quality advocators used to describe that quality is free [11]. In fact, nowadays research and practice on quality might have neglected some important aspects of quality competition. Reviewing the fundamental economic principles on quality will help to settle the controversies and implement more effective quality management.

\section{Customer-Defined Quality}

Quality is primarily a matter of product differentiation and competition. Wallace [12] referred to product differentiation as "a symptom of greater precision in the satisfaction of wants" and to "those sort and degrees of variation of product which better meet the wants of consumers." Chamberlin [13] noticed the problem of "adapting the product more exactly to buyers' wants" and of wants being "more exactly satisfied with a differentiated product." Duesenberry [14] pointed out that "almost any activity can be carried out in a variety of ways and variety of goods can be used to implement it. ... The goods which can be substituted for one another for a single purpose ... are qualitatively different ways of doing the same thing. Even more important, they are not just different but some are better than others." Especially, Abbott [15] clarified, summarized and emphasized in the sense of the economic role of quality in modern industrial society.

Before Abbott, the economic theory of market competition mainly focused on price competition, while quality comparisons were explained by the principle of substitution. Quality competition was often ignored. Abbott linked consumer's and producers' choice of quality to basic wants and argued that "socially useful entrepreneurial activity consists not only of activity dealing with production methods, cost, output, and prices, but also of (a) activity that seeks to achieve precision in satisfying wants ..., and (b) activity that seeks to achieve greater precision by altering the quality of the products." He noted that the diversity of people's wants determines the inevitability of product heterogeneity. Products must be differentiated and precisely produced 
for certain customers' certain wants. He distinguished basic want--the desire for an experience--and derived want--the desire for a product which actually or supposedly provides the means to that experience. Since the product provided by the producers may imperfectly satisfy peoples' desire for the experience, there are always room for producers to adjust the quality of the product toward the goal of perfect satisfaction. Further from Schumpeter's theory of economic development, Abbott emphasized that quality competition-companies' struggle on providing products that better satisfy people's wants--is as important as price competition for the economic development of the society.

In terms of the level of precision that a product satisfies customers want, quality is measured inversely proportional to the variability around the expectation. In modern industrial society, most of the products wanted by consumers are fabricated. A firm's product may be raw materials and intermediate product rather than directly consumed by consumers, but the ultimate purpose of the existence of this product is to form a final product for consumption. The variability of raw and intermediate products also determines, through the final product, the precision of consumers' satisfaction. Products are designed to eventually satisfy consumer's wants. Quality control guarantees the products are produced according to product design. It controls the variability of the product at acceptable levels that defines the precision of satisfaction of wants. Quality improvement achieves greater precision of production by reducing the variability of output. A product of low quality is one having too much variability, or is wrongly produced as something different from what customers really want. In either case, the customers are not satisfied with the product and will be motivated to seek other products that may potentially satisfy them. And this potential alternative product is usually available from a competitor.

As Abbott noted, most of the markets in modern market economy are imperfect markets, something between pure competition and complete monopoly A complete economic competition includes two dimensions, price competition and quality competition. Three kinds of quality differences can induce quality competition. Vertical difference in quality may properly be described in terms of "higher" or "lower", for all rational buyers according to the costs the goods entail or the physical properties the goods contain in the sense of superior versus inferior. For example, a watch made with diamond has higher quality than a watch made just of steel. Horizontal difference generates dissimilar qualities for different buyers who differ in circumstance, values and tastes and rank dissimilar qualities in different order, where cost differences, if any, are purely incidental. Example includes different color, shape, or style of design for the same product. Innovational changes are considered "improvements by most of the buyers, yet involve no significant increase in cost or else. Manufacturing, operation, and management innovations, including the adoption of better quality control techniques, may induce improvements in quality of this kind. The first kind in above, vertical differences, creates different levels of quality so that two broad kinds of quality competition can be distinguished:

1. competition between quality levels, and

2. competition within quality levels.

Note that the cost in the above we are talking about is, in the sense of accountancy, mainly variable cost rather than fixed cost. It is the variable cost that distinguishes the first kind of quality differences, vertical changes, and the third kind of quality differences, innovational changes. Strictly speaking, quality is not free. If fixed cost is included in the context, any quality differentiation will entail cost. Quality failure incurs loss. Quality control reduces the cost of quality failure but adds to the cost for appraisal and prevention. Quality improvement requires such money input as experiments and teamwork of experts from various fields, while it may help to produce better products. Furthermore, quality differentiation will sector a certain market into sub sectional markets so that cost issue may arise from the diseconomies of smaller-scale production of each subsection. The joint effect of all these sources, which can be called the total quality cost, may be minimized but will not be zero, and it will be reflected in the price of the product.

Since customers' income is limited and dissimilar, what eventually determines a customer's purchasing decision is his utility. A customer allocates his income to pay for products and service to realize the experience that maximizes the general satisfaction of his various wants. When customers pay for a product to satisfy part of their desires, with a limited income, they may lose the opportunity to satisfy their other desires. Quality is then not only a property of the product itself, but also a reference correlated to other products. All in all, it can be seen that the quality management movements in the past decades reflect the disequilibrium of economic competition. Along with the globalization of economy, companies encountered both price and quality competition from rivals all over the world. When price reduction is not realistic or not enough for companies to diminish the utility gap created by the rivals, quality differentiation becomes the only choice in order to move toward the (never-accomplishable) equilibrium. Also, investing in quality improvement is a right decision only when customers are able to afford the changed (usually increased, if the total quality cost is positive) price, and willing to enjoy the experience provided by the improved (if any) product.

The disequilibrium also arises from the changeability of customers' wants. Even if a product can precisely satisfy customers' current wants, it does not satisfy them if their wants change. Due to human instinct, customers' satisfaction on one product will inevitably decline, and compensation to this decline is need, often in the form of satisfaction of new wants. As early economists [16,17] noted, a typical customer behaves in a multi-price market by asking himself "Would I prefer to have Product A, or to have Product B and, in addition, C dollars of income to spend on other things?" It may happen frequently that a customer rejects or stops buying the product which best satisfies or used to best satisfy his wants, and switches to favor some non-optimal, less expensive product. Companies have to unceasingly examine, monitor, and discover customers' new wants, then develop and provide products to satisfy the newly discovered demand of wants. The winner in the competitive market is the firm who can always provide products and service that contribute to keep or increase customers' optimal utility. By endless quality competition, companies are developed, customers are satisfied, and the welfare of the whole society is increased.

It should be also noted that in a market of disequilibrium, the tendency or speed a customer switch his purchasing decisions is proportional to the gradient of his utility function with respect to the other options. Thus the effectiveness of quality management measures on business performance in the market is actually determined not only by the measures themselves, but more by the performance of its rivals. The right decision on implementing quality approach depends on the right perspective on the situation of the market and status of the competitors. 
In sum, quality management initiatives should indeed pay significant attention to bottom line. Companies should be always aware that with limited payment ability, customers will, in general, look for lower prices in order to use the save 1) to purchase other experiences, i.e., to satisfy other wants, and/or 2) to compensate the declined satisfaction to the ongoing experience. This is a challenge for producers that they have to balance the pressures of reducing price and maintaining/differentiating/improving quality. The producers have to 1) reduce the cost while maintain the quality, and/or 2) differentiate/ improve the quality unceasingly but without charging more. Many companies actually failed in market competition due to misdealing with this matter. Specifically, either focusing on quality but losing the bottom line, or vice versa, keeping prices unchanged without improving quality, will lead the company's products target at wrong customer groups whom are not supposed to be aimed at. And this incorrect target may be in vain or less effective so that the company fails accomplishing its business goal. Therefore, customer-defined quality requires that the products or service must be produced for and delivered to the exactly same customers who define it. This should be the rule to assess good or bad practice of quality management.

\section{The Abstract Definition: Quality vs. Risk}

Noting quality is the measure of the level of precision that customers satisfy their wants while constrained by the allocation of their payment ability, we may now further to discuss the abstract definition of quality. It is well known in literature that quality is inversely proportional to variability. In mass production context, it is a term of consistency. In statistics, variability is usually referred to the second moment variation. And this is actually what the up-to-date quality studies are concerned. However, based on the principle of customers' utility, more complex aspects should be considered. The higher moments may also affect quality. The current term of the definition of quality, variability, would be better modified as uncertainty to capture not only the second but also the higher moments. In fact, although the term uncertainty is often used by quality researchers and practitioners, it usually means (second moment) variation instead of implying and specifying the difference between these two terms, and higher moments of the probabilistic uncertainty were ignored.

Moreover, it is actually the downside rather than the upside uncertainty measures the quality. Using the term variability or variation does not accurately depict the whole characteristics of quality. First, to see the role of higher moments in quality, suppose two products have the same mean and variability, i.e., the first and second moments. If one product has higher skewness or kurtosis than the other, the utilities for customers who purchase and use the products are different. For risk-averse customers who want precision, the product of higher kurtosis (fat at tails) provides less utility, i.e., less satisfaction, because higher kurtosis means larger chances for large deviations. This can be seen from the fat tails of the probability distribution of higher kurtosis. Similarly, the right skewness may be preferred to the left skewness, or vice versa, depending on the specific design requirements of the products. For example, suppose a machine component, say, a metal axis, requires precise diameter, and according to the design and mechanism of the machine it is more tolerant to have a smaller diameter than a larger diameter. Then a higher positive skewness in diameter means worse quality even if the variance keeps the same. Therefore, uncertainty, which includes the second and higher moments, is a more appropriate term than variability to define quality. This issue has been noted and investigated in risk-related studies (e.g., in finance literature researchers tried to modify the meanvariance framework of capital asset pricing model by considering the effects of higher moments). Practitioners also have been intuited this, though perhaps not in explicit terms, for a long time. However, it has little been a research topic in academic quality literature.

Secondly, customers can be satisfied and over-satisfied for their wants. That is, for customers' expected wants, products that can provide satisfaction and products that can provide even more than the satisfaction are all welcome by the customers (as long as they afford and are willing to pay the products). Customers only dislike the products that can not satisfy their wants. What they dislike is not simply the uncertainty, but often the downside uncertainty. In the cases they welcome the upside uncertainty, quality should be defined as being inversely proportional to downside uncertainty. Of course, in most cases only the consistency or precision--with both sides--defines and measures quality. Examples include most of the medium-process products, because the next processes usually do not allow significant departures, either downside or upside, from the target.

When quality is measured by downside uncertainty, whether the uncertainty is a symmetric distribution affects the result of measurement for quality. For consumer's products, the satisfactionrelated uncertainty perceived by consumers is usually skewed due to human taste behavior. When skewness exists, the asymmetry of distribution causes the downside measurement for quality different from the double side measurement, while in symmetric (zero skewness) distributions whether to distinguish downside or double side does not matter, for each side gives the same uncertainty. Therefore, to correctly measure quality and evaluate the effects of quality, we should additionally measure and control the higher moments of the uncertainty.

The abstract definition allows us to examine more about quality and uncertainty. In some special cases where customers seek experiences to satisfy their wants through taking risk, the concept of quality being consistency or inversely proportional to uncertainty is more complicated. Special products are preferred to have properties of diversity or uncertainty. Quality is then the precision of the desired uncertainty or diversity. One of these examples is lottery product. Consumers prefer to buy numbers from a pool of large variety rather than from a narrow range. Here, the consumers' expectation about quality can be the diversity of the numbers at retail site of the lottery (Note that directly relating quality to customers' original want, which is to win millions of dollars, is obviously inappropriate). If the retail site has only narrow range of numbers, there is then a departure from consumers' requirements, thus it is selling low quality product.

The quality of financial products pertains to a more general domain. Financial products are differentiated for their expected returns and risks, where risk is defined by the uncertainty--actually the downside-of future return, and measured by usually the second moment, more elaborately the higher moments. The higher risk of the product, the higher return is required to compensate the risk. A buyer of financial product wants two things: high return and low risk, both of which are determined by market. Like in purchasing physical products and quality, customers have to compromise between return and risk, and maximize their utility. Two similarities exist: the expected return resembles the negative of the price to pay for a product; the risk resembles the opposite to the quality of the product. In other words, the quality of a financial product can be measured by the deviation of the realized return from the claimed or expected return. 
Page 4 of 5

Taguchi [8,9] described the relationship between quality and uncertainty from the viewpoint of loss function. Second-order Taylor series expansion is usually used and higher-order items omitted to approximate customers' dissatisfaction, measured as loss of money, in terms of departure from their wanted target. As a matter of fact, the dissatisfaction can be just viewed as the decrease of utility. Therefore, Taguchi loss function can provide a vehicle of dealing with the tradeoff between utility and uncertainty.

From the above discussion, we can see that quality and risk have common characteristics in their abstract concepts. Quality is inversely proportional, and risk is proportional, to uncertainty. Quality may be viewed as negative risk. In most cases, risk is directly related to the amount of money, while quality has more dimensions that may be indirectly translated to money, via utility. Thus, the analytical methods in one area may be introduced to use in the other. In fact, statistical tools are popularly applied in both areas. Like the systems thinking in quality management area, such as Total Quality Management, risk management researchers suggested to synthesize the approaches and initiate Total Risk Management [18]. On the other hand, the fruitful results in risk studies can also benefit the understanding of quality. The similarity between quality and risk may lead the two areas eventually form a unified theory.

\section{Quality-Based Product Portfolio}

On the basis of the above discussions, we are now able to construct the concept of quality-based product portfolio. From utility viewpoints, a framework of the trade-off between benefits of quality and the price of the products or service can be established, similar to that in financial economics where the expected equity return is compensated with the risk that is measure by uncertainty. In the first and second moment framework, capital market pricing model (CAPM) [19-21] is good enough for reference.

In finance, portfolios are used to diversify the risks that each individual asset would have entailed if it were held separately. Basically there are two kinds of diversification being used in financial practice: cross-asset diversification and time diversification, where the former is much more popular than the latter. Cross-asset diversification is to diversify the total amount of the investment into various assets, for example, different stocks, with each asset sharing its certain percentage weight of the total amount of the portfolio. CAPM model concerns mainly this type of portfolio. Time diversification, particularly studied by Samuelson [22-24], is to diversify the investment over time with each time investing part of the whole.

Can customers consume non-financial products or service in the way of portfolios of products or service? Or, do they prefer portfolio of products or service to individual items? The answer seems generally a YES, although the issue has been little studied. It should be noted that with the budget constraint of the total amount of the portfolio, the price-quality compensation problem is often transformed to quantityquality compensation problem. For example, you have two dollars and can consume one bag of popcorn of high quality at $\$ 2 / \mathrm{lb}$, but you may alternatively consume two bags of low quality popcorn at $\$ 1 / \mathrm{lb}$. The second choice, two bags of cheaper popcorn, is a portfolio versus the first choice of individual product.

Whether or not the utility of consuming one bag popcorn of higher quality is higher than that of consuming two bags popcorn of lower quality differs from one consumer to another. The combined quality of the two bags of popcorn depends on the correlation between each bag.
In general it is given by $\sigma_{p}^{2}=\sigma_{1}^{2}+\sigma_{2}^{2}+2 \rho \sigma_{1} \sigma_{2}$. In this specific example it is reasonable to think each bag of the product is produced independently $(\rho=0)$ even from the same production line $\left(\sigma_{1}^{2}=\sigma_{2}^{2}\right)$ hence, $\sigma_{p}^{2}=\sigma_{1}^{2}+\sigma_{2}^{2}=2 \sigma_{1}^{2}$. The quality of the $\$ 2 / \mathrm{lb}$ bag is $\sigma_{0}^{2}$, which is smaller than $\sigma_{1}^{2}$. Suppose the maximum utility is $U_{0}$ (which corresponds to the case the product is exactly what is wanted), then the utilities for the two options in this example are respectively measured as $U_{0}-k \sigma_{0}^{2}$ and $2\left(U_{0}-k \sigma_{1}^{2}\right)$, where $\mathrm{k}>0$ is similar to that in Taguchi loss function, and consuming two bags doubles the utility. Thus, the critical $\mathrm{k}$ value giving the same utility is $k_{c}=U_{0} /\left(2 \sigma_{1}^{2}-\sigma_{0}^{2}\right)$. When $k>k_{c}$, consuming one bag of $\$ 2 / \mathrm{lb}$ popcorn is preferable, and when $k<k_{c}$, consuming two bags of $\$ 1 / \mathrm{lb}$ popcorn is preferable. It is easy to see that if $\rho \neq 0$ and $\sigma_{1}^{2} \neq \sigma_{2}^{2}$, the critical $\mathrm{k}$ value is $k_{c}=U_{0} /\left(\sigma_{1}^{2}+\sigma_{2}^{2}+2 \rho \sigma_{1} \sigma_{2}-\sigma_{0}^{2}\right)$. Different customers may make different choices, because they have different $\mathrm{k}$ and $U_{0}$. For the same customer, different products also have different $\mathrm{k}$ and $U_{0}$ so that he may prefer an individual product for one want but a product portfolio for another want. This discussion can be easily extended to more components in the portfolio, and each component does not have to be the same product. The component products may have dissimilar quality; their correlation may be nonzero. For continuous quantities (e.g., oil cannot be counted by pieces, but by continuous weight or volume), the counting of utility needs just a little modification. For example, consider the two choices of $a_{0}$ amount of an identical product $P_{0}$ and an n-component product portfolio of weights denoted as vector $\vec{b}=\left(b_{1}, b_{2}, \ldots, b_{n}\right)^{\prime}$, and uncertainty denoted as covariance matrix $\Sigma$. Define the unit maximum utility is $u_{0}$ (corresponding to zero uncertainty), and the unit coefficient $k^{\prime}$. The utilities for the two choices are respectively $a_{0} u_{0}-a_{0} k^{\prime} \sigma_{0}^{2}$ and $\left(b_{1}+b_{2}+\ldots+b_{n}\right) u_{0}-k^{\prime} \vec{b}^{\prime} \Sigma \vec{b}$. The critical unit $k^{\prime}$ is then $k_{c}^{\prime}=\left(b_{1}+b_{2}+\ldots+b_{n}-a_{0}\right) u_{0} /\left(\vec{b}^{\prime} \Sigma \vec{b}-a_{0} \sigma_{0}^{2}\right)$,

Where, the unit $k^{\prime}$ transforms the uncertainty for consuming unit amount of the product into dissatisfaction. The weights $a_{0}$ and $b_{1}, b_{2}, \ldots, b_{n}$ are constrained by the prices $p_{0}, p_{1}, \ldots, p_{n}$ and the total budget $\mathrm{M}$ that is allowed to spend in purchasing the satisfaction of this specific want: $a_{0} p_{0}=b_{1} p_{1}+b_{2} p_{2}+\ldots+b_{n} p_{n}=\mathrm{M}$.

More important, the supply and demand in the market of the products will also drive the prices to move toward the equilibrium, and eventually form efficient product portfolio similar to something like the efficient frontier in CAPM theory. That is, if a group of customers prefer an individual product rather than a product portfolio, the demand for the component products of that portfolio will decrease, the prices for them will then decrease. Due to the budget constraint (2), the weights $b_{1}, b_{2}, \ldots, b_{n}$ can increase to induce the utility of the product portfolio to increase until it reaches the utility of the individual product at which the prices for the portfolio products stop decreasing. On the other hand, if initially the product portfolio is preferred in the market, the price for the individual product will then 
Page 5 of 5

decrease due to lacking demand. And finally the weight for the individual product increases so that induces the utility until it has the same utility as the product portfolio. Consequently, a well-constructed quality-based product portfolio can be always fount to substitute any specific product to provide the customers the same quality or satisfaction. Only the portfolios that are at least as competitive as the individual products are efficient and will be actually constructed. The premise this kind of equilibrium is realizable is that the prices of the products are determined and adjusted by the market instead of the production costs. The products that cannot compete to their corresponding quality-based portfolios will be naturally dropped off.

In quality-based product portfolio both cross-category diversification, which resembles cross-asset diversification in financial products, and time diversification can have the form of quantityquality tradeoff. Unlike in financial products where time diversification is unpopular, in our context of quality-based product portfolio time diversification may be more popular than cross-category diversification, because it is often the nature that people use products one by one rather than use them simultaneously. (A customer may prefer repeatedly buying new Pontiac's with using each one just a few years, to buying one Mercedes-Benz and keeping it for twenty years, even though the quality of the latter may allow it to last that long time.) A portfolio of time diversification can last until the end of the customer's life. With time diversification, it is always possible that a customer include some component products in the portfolio some days later so that the general satisfaction to one kind of specific want is ultimately balanced to a certain level. Thus, the customer can use his limited income to purchase more various experiences at one and postpone the purchase of more expensive experiences to the future. Or, he may use all his current payment ability (even borrow money) to purchase what he wants the most, and then diversify the products to coordinate with his income expectation. This allows a rational customer to balance his short run and long run satisfaction of his wants so that his general utility can be maximized.

Since a product will face the competition not only from other individual products, but also from a product portfolio, the market competition is intensified. The quality based product portfolio is a remarkable characteristic of quality competition and should be paid sufficient attention in quality management. Otherwise, the company will not yield desired return.

\section{Summary}

In sum, quality is the consequence of product differentiation and competition. It is driven by customers' wants and derived from discovering and differentiating customers wants and measured by the certainty or precision of the satisfaction of these wants. In abstract definition, quality is inversely proportional to uncertainty. It is negative risk. Like financial products, physical product and non-financial service can be also selected to form quality-based product portfolios. The product portfolio can diversify the uncertainty of individual product and substitute individual product to provide the same satisfaction of wants. A preliminary theory and analytical framework of quality-based product portfolio was proposed in this paper. The efficient product portfolio is determined by the market movement toward equilibrium. The conclusions from quality-based product portfolio provide a new angle to view quality and quality competitions, hence is potentially helpful to improve quality management.

\section{References}

1. Montgomery DC (1997) Introduction to Statistical Quality Control, third edition, John Wiley \& Sons, inc., New York, USA.

2. Shewhart WA (1931) Economic Control of Quality of Manufactured Product, D. Van Nostrand Company, Inc., New York.

3. Shewhart WA (1939) Statistical Method with the View Point of Quality Control. Dover Publication, New York.

4. Deming WE (1944) Some Principles of the Shewhart Methods of Quality Control. Mechanical Engineering 66: 173-177.

5. Deming WE (1982) Quality, Productivity and Competition Position, MIT Press, Cambridge, MA, USA.

6. Deming WE (1986) Out of Crisis, MIT Press, Cambridge, MA, USA.

7. Taguchi G, Wu Y (1980) Introduction to Off-Line Quality Control, Japan Quality Control Organization, Nagoya, Japan.

8. Taguchi G (1986) Introduction to Quality Engineering, Asian Productivity Organization, UNIPUB, White Plain, NY, USA.

9. Taguchi G (1986) Introduction to Quality Engineering: Designing Quality into Products and Processes, Asian Productivity Organization, Tokyo, Japan.

10. Gryna F (1994) Quality and Cost. Juran Quality Handbook (5thedn) by J. Juran and A. B. Godfrey, McGraw-Hill, NY, USA.

11. Crosby PB (1980) Quality is free: the art of making quality certain, New York : New American Library.

12. Wallace D (1936) Monopolistic Competition and Public Policy. American Economic Review: Papers and Proceedings 26.

13. Chamberlin EH (1933) The Theory of Monopolistic Competition. The Economics Journal 43: 213.

14. Duesenberry J (1949) Income, Saving, and the Theory of Consumer Behavior, Harvard University Press, Cambridge, USA.

15. Abbott L $(1955,1973)$ Quality and Competition, Greenwood Press, CT, USA. First published by Columbia University Press, NY, USA.

16. Clark JB (1900) The Distribution of Wealth, New York, Macmillan.

17. Norris RT (1941) The Theory of Consumer's Demand (1stedn) New Haven, Yale University Press, USA.

18. Andrew L (1999) The Three P's of Total Risk Management. Financial Analysts Journal 55: 13.

19. Markowitz H (1952) Portfolio Selection. Journal of Finance 7: 77-91.

20. Sharpe W (1964) Capital Asset Prices: A Theory of Market Equilibrium under Conditions of Risk. Journal of Finance 19: 425-442.

21. Mossin J (1966) Equilibrium in a capital asset market. Econometrica: 34: 768-783.

22. Samuelson P (1963) Risk and uncertainty: A fallacy of large numbers. Scientia, 6th Series, 57 th year.

23. Samuelson P (1969) Lifetime portfolio selection by dynamic stochastic programming. Review of Economics and Statistics 51: 239-246.

24. Samuelson P (1989) The judgment of economic science on rational portfolio management: Indexing timing, and long-horizon effects. Journal of Portfolio Management 16: 4-12. 